\title{
Assessment of the Glaucomatous Patient
}

\author{
GEORGE L. SPAETH, and ROHIT VARMA
}

William and Anna Goldberg Glaucoma and Research Laboratories, Wills Eye Hospital/Thomas Jefferson University Philadelphia

This paper will be limited to discussion of the patient with primary open-angle glaucoma. Gonioscopy, then, must already have been done and have demonstrated the angle to be open and normal. Of course, monitoring the angle changes with age and in response to other events is an essential part of the continuing evaluation of the patient with openangle glaucoma and periodic gonioscopy, repeated at about yearly intervals should be done. Gonioscopy may need to be performed more frequently in those patients in whom the angle is open but is sufficiently narrow that angle-closure could become a factor. Furthermore, the relationship between traumatic cleavage of the angle ${ }^{1}$ and the exfoliation syndrome and its associated pigmentation and open-angle glaucoma ${ }^{2}$ should be remembered.

There are two quite independent aspects of the assessment of the patient with primary open-angle glaucoma:

(1) diagnosis

(2) management.

There is no 'pregnancy test' for glaucoma, not even primary open-angle glaucoma. Because of the multifactorial nature of the disease, even of primary open-angle glaucoma, it seems unlikely that there ever will be a single diagnostic test that will allow the ophthalmologist to rule out glaucoma on the basis of that test alone. The essence of the quandary is that glaucoma is a disease of intraocular pressure, but, because of individual variability in the resistance of each patient to the damaging effects of intraocular pressure, the disease cannot be said to be present with complete certainty in the absence of structural and func- tional change. Compounding the quandary is the belief that abnormal intraocular pressure is the precursor to the damage; as a consequence, most treatment is aimed at lowering intraocular pressure in order to prevent damage. The outcome of this situation is that the ophthalmologist does his or her best to prevent the development of those findings necessary to ascertain the diagnosis. Therefore, many patients are treated for many years without a diagnosis ever having been established definitively. While this is fundamentally distasteful, it remains the reality, and will undoubtedly continue to be the reality in the forseeable future.

The three considerations that have been studied sufficiently to permit standardisation and attribution of significance regarding presence or absence of disease are intraocular pressure, appearance of the optic disc, and the nature of the visual field. ${ }^{3}$ Many other factors are undoubtedly abnormal in patients with glaucoma, such as contrast sensitivity, ability to discern flicker, dark adaptation, colour perception, and responsiveness of the intraocular pressure to corticosteroids. In addition, it is clear that a variety of factors increase the risk that a person will develop actual glaucomatous disease: Obesity, a positive family history, diabetes mellitus, low blood pressure, myopia, Negroid ancestry, systemic hypotension, and increasing age.$^{4-5}$ None of these factors, alone or in combination, is sufficient to establish a diagnosis, and they remain at best ancillary modifiers that, added to consideration of three primary factors, make the ophthalmologist push therapy more or less vigorously. Table I presents one format allow- 
Table I Criteria Necessary to Establish a Diagnosis of Primary Open-Angle Glaucoma*

\begin{tabular}{|c|c|c|}
\hline Intraocular pressure & Optic disc & Visual fields \\
\hline $\begin{array}{l}\text { 1. } 40 \mathrm{~mm} \mathrm{Hg} \text { on } 3 \text { separate occasions at least one } \\
\text { month apart }\end{array}$ & Any appearance & Any appearance \\
\hline 2. $30 \mathrm{~mm} \mathrm{Hg}$ on 3 occasions at least one month apart & Suspicious disc ${ }^{* *}$ & Suspicious field** \\
\hline $\begin{array}{l}\text { 3. Above } 21 \mathrm{~mm} \mathrm{Hg} \text { on } 3 \text { occasions at least one } \\
\text { month apart }\end{array}$ & Definite disc defect** & Suspicious field defect** \\
\hline $\begin{array}{l}\text { 4. Above } 21 \mathrm{~mm} \mathrm{Hg} \text { on } 3 \text { occasions at least one } \\
\text { month apart }\end{array}$ & Suspicious disc ${ }^{* *}$ & Definite field defect** \\
\hline 5. Any level of intraocular pressure & Definite defect** & Definite defect** \\
\hline
\end{tabular}

*In all cases the anterior chamber angle is open and normal and history and examination uncover no ocular or systemic cause for elevated intraocular pressure, optic atrophy, or visual field loss.

**See text for definition of suspicious and definite disc and field defects.

ing the ophthalmologist and the patient to be reasonably sure that primary open-angle glaucoma is present.

When the intraocular pressure is consistently above $40 \mathrm{~mm} \mathrm{Hg}$ the likelihood that the optic nerve will become damaged in a period of months is so great as to be virtually certain. When the pressure is above $30 \mathrm{~mm} \mathrm{Hg}$ the likelihood is that most individuals will eventually develop glaucomatous optic nerve damage, although such a change may take many years. Intraocular pressures consistently below $21 \mathrm{~mm} \mathrm{Hg}$ are not the rule in patients with glaucoma, but they are sufficiently frequent that low intraocular pressure cannot be used to rule out the presence of glaucoma. Indeed, around one-third of patients with glaucoma will have isolated measurements of intraocular pressure below $21 \mathrm{~mm} \mathrm{Hg}^{6}$

Variability in the appearance of the disc and field is also great. The cup/disc ratio itself is of small assistance. For while it is true that the larger the cup the greater the likelihood that glaucoma is present, the range of variability is so great that taken by itself, cup/disc ratios are of little help unless .8 or greater, in which case the disc should be considered suspicious. The presence of an isolated notch on the rim or of a superficial haemorrhage on the disc rim also makes the disc highly suspicious for glaucoma. Where the thickness of the rim is less than 0.1 of the disc or there is a complete absence of disc tissue, (especially when this

Table II Relative Ability of Different Methods to Detect Change in the Visual Fields*

\begin{tabular}{|c|c|c|c|}
\hline Early disease & Marked disease & Advanced disease & $\begin{array}{l}\text { Very } \\
\text { far-advanced disease }\end{array}$ \\
\hline $\begin{array}{l}\text { Full field computerised static } \\
\text { perimetry (such as Octopus } \\
\text { Perimetry Program G1) }\end{array}$ & $\begin{array}{l}\text { Computerised static, } \\
\text { threshold spatially adaptive } \\
\text { perimetry }\end{array}$ & $\begin{array}{l}\text { History } \\
\text { Repetitive, } \\
\text { averaged threshold }\end{array}$ & $\begin{array}{l}\text { Confrontation field } \\
\text { with light } \\
\text { History }\end{array}$ \\
\hline $\begin{array}{l}\text { Computerised static perimetry } \\
\text { of central field with } \\
\text { repeated accurate threshold } \\
\text { determinations }\end{array}$ & $\begin{array}{l}\text { Computerised threshold static } \\
\text { full field perimetry } \\
\text { Computerised static perimetry } \\
\text { Kinetic perimetry with }\end{array}$ & $\begin{array}{l}\text { static, spatially } \\
\text { limited perimetry } \\
\text { Tangent screen at } \\
\text { two meters }\end{array}$ & Kinetic perimetry \\
\hline $\begin{array}{l}\text { Kinetic perimetry combined } \\
\text { with on-off non-threshold } \\
\text { presentations }\end{array}$ & $\begin{array}{l}\text { multiple isopters and on-off } \\
\text { non-threshold determinations } \\
\text { History }\end{array}$ & $\begin{array}{l}\text { Kinetic perimetry } \\
\text { Confrontation field } \\
\text { Automated non- }\end{array}$ & \\
\hline $\begin{array}{l}\text { Kinetic perimetry with } \\
\text { multiple isopters }\end{array}$ & $\begin{array}{l}\text { Kinetic perimetry multiple } \\
\text { isopters }\end{array}$ & threshold perimetry & \\
\hline $\begin{array}{l}\text { Automated, static, non- } \\
\text { threshold perimetry }\end{array}$ & $\begin{array}{l}\text { Automated, non-threshold } \\
\text { static perimetry }\end{array}$ & & \\
\hline History & Confrontation field & & \\
\hline
\end{tabular}

\footnotetext{
* Most sensitive technique listed first
} 


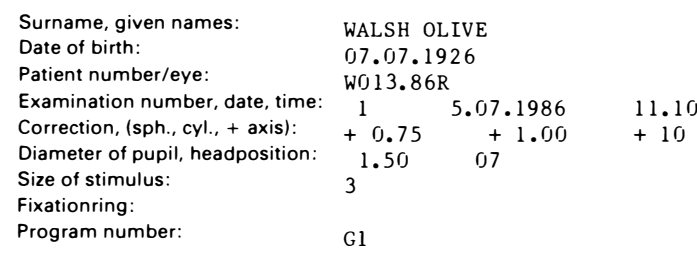

OCTOPUS

$\begin{array}{lclcl}\text { Number of questions: } & 475 & \text { Number of repetitions: } & 0 & \text { Date of printout: }\end{array}$ 6.17.1986

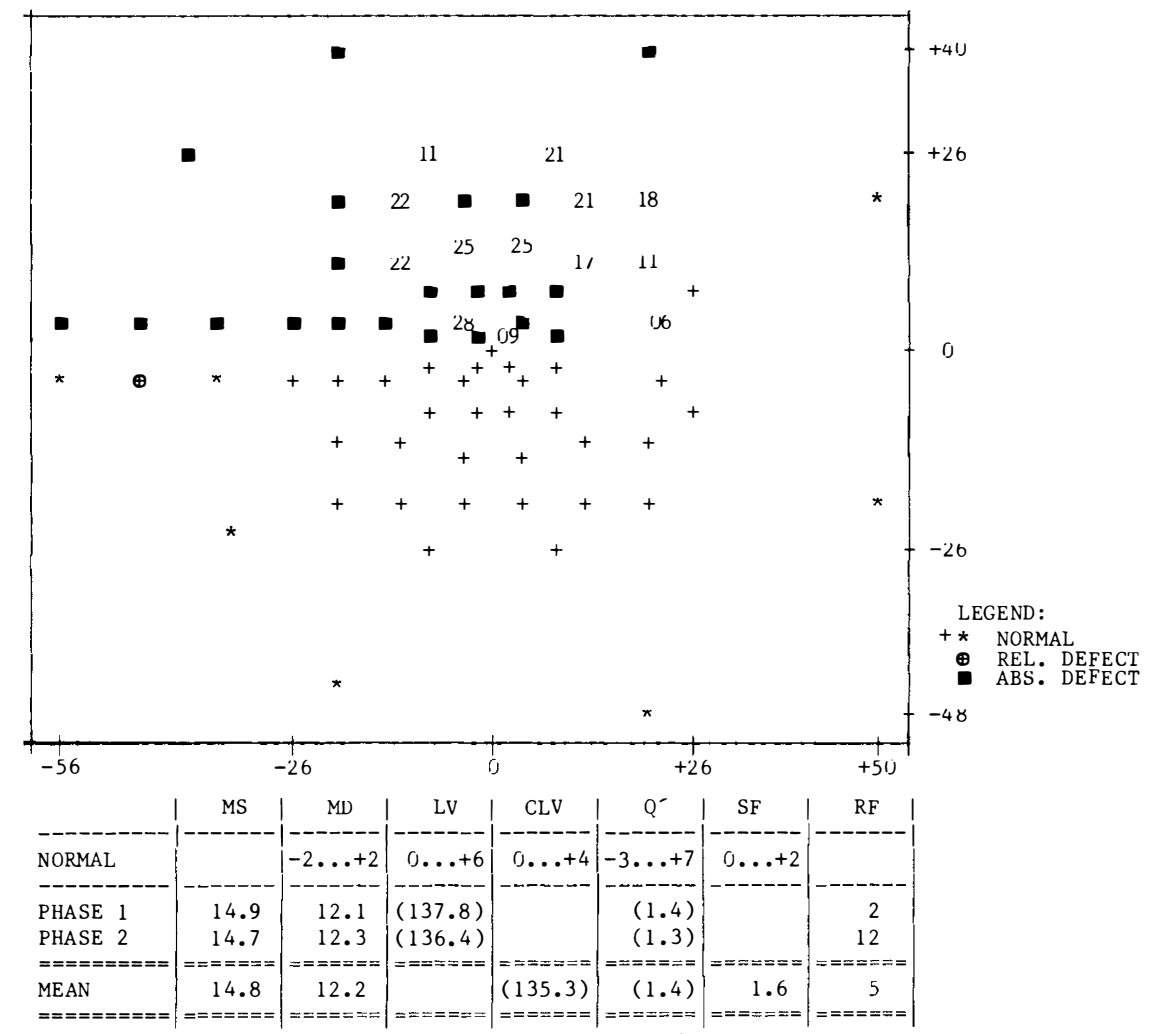

\begin{tabular}{|c|c|c|c|c|c|c|c|c|c|}
\hline Symb. & ::: & :::: & ::: & $\because::$ & :๕: & $8: 8$ & 73 & 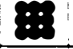 & \\
\hline$d B$ & $51-36$ & $35-31$ & $30-26$ & $25-21$ & $20-16$ & $15-11$ & $10-6$ & $5-1$ & 0 \\
\hline asb & $\begin{array}{c}0,008- \\
0,25\end{array}$ & $\begin{array}{c}0.31- \\
0,8\end{array}$ & $\begin{array}{l}1- \\
2,5\end{array}$ & $\begin{array}{c}3,1- \\
8\end{array}$ & $\begin{array}{c}10- \\
25\end{array}$ & $\begin{array}{c}31 . \\
80\end{array}$ & $\begin{array}{c}100- \\
250\end{array}$ & $\begin{array}{c}315- \\
800\end{array}$ & 1000 \\
\hline
\end{tabular}

CILCO, IIIC.

1616 13th Avenue

Huntington, West Virginia 25717

Fig. 1a.

asb $=0,318 \mathrm{~cd} / \mathrm{m}^{2}$

Fig. 1. A visual field determined with the Octopus Computerised Perimeter using Program G1. This is an example of the type of information that can be obtained using a computerised static perimeter that determines actual thresholds. The data can then be manipulated to provide means of various parameters, including the standard deviation and comparison to normal means and ranges, for example: The mean sensitivity of the spots tested (MS), the mean loss over the entire field (mean defect-MD), the likelihood that a localised area of change represents a real difference from the threshold area of change represents a real difference from the threshold at other areas of the field (loss variance- $L V)$, loss variance corrected for scatter and short-term fluctuation (corrected loss variance-CLV), the variability of a threshold as determined repeatedly at the same location (short-term fluctuation-SF), and the ability of the patient to respond positively when presented with an object able to be seen and negatively when presented with an object not able to be seen (reliability factor-RF). The conjoint use of these parameters is of great assistance in allowing a valid distinction between real change and mere variability. 


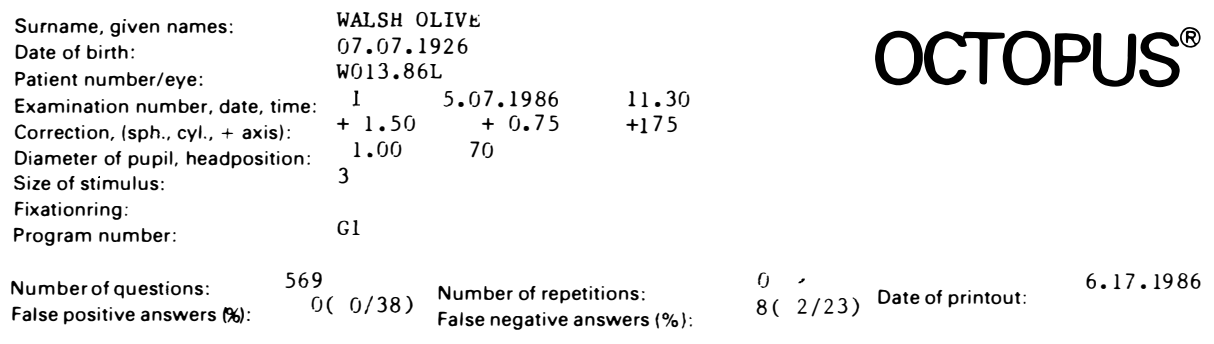

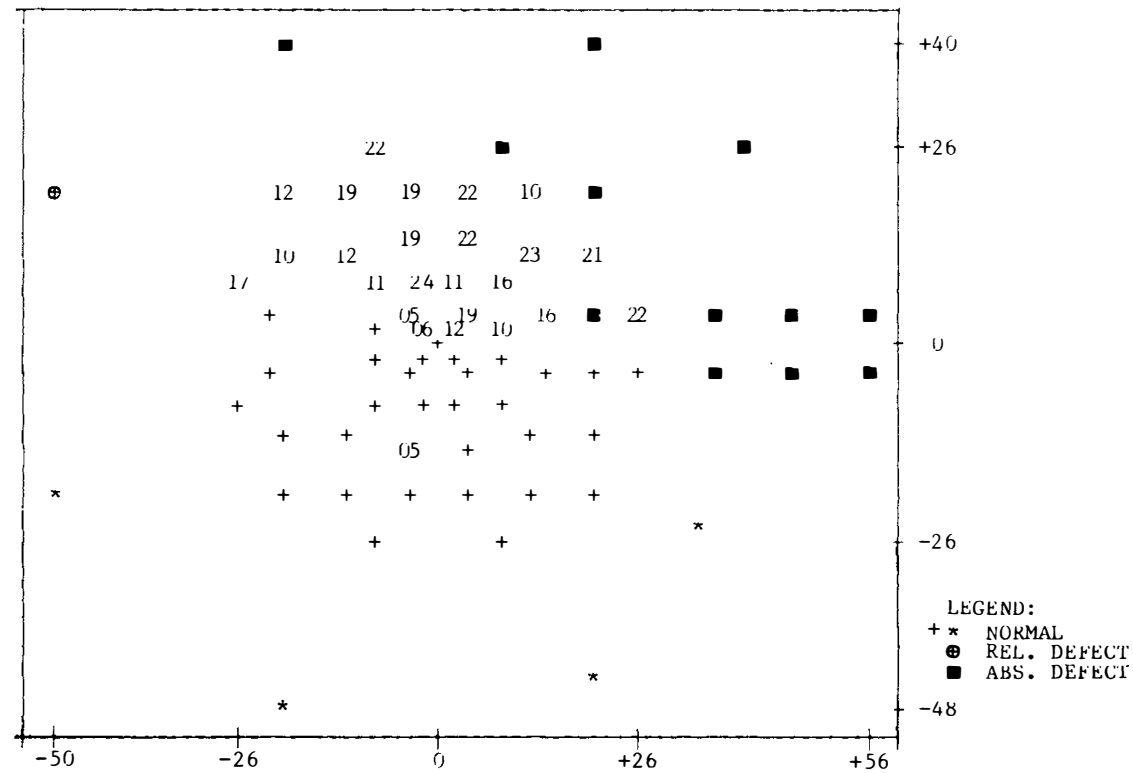

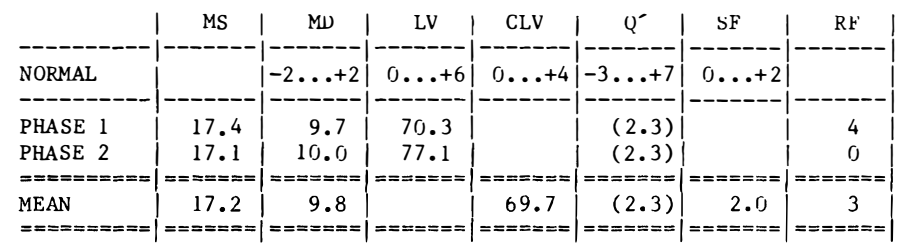

\begin{tabular}{|c|c|c|c|c|c|c|c|c|c|}
\hline Symb. & $:::$ & $:::$ & ::: & :::: & בE: & 888 & If & $\vdots$ & \\
\hline$d B$ & $51-36$ & $35-31$ & $30-26$ & $25-21$ & $20-16$ & $15-11$ & $10-6$ & $5-1$ & 0 \\
\hline asb & $\begin{array}{c}0,008- \\
0,25 \\
\end{array}$ & $\begin{array}{c}0,31- \\
0,8\end{array}$ & $\begin{array}{l}1- \\
2,5\end{array}$ & $\begin{array}{c}3,1- \\
8\end{array}$ & $\begin{array}{l}10- \\
25\end{array}$ & $\begin{array}{c}31- \\
80\end{array}$ & $\begin{array}{c}100- \\
250\end{array}$ & $\begin{array}{c}315- \\
800\end{array}$ & 1000 \\
\hline
\end{tabular}

1 asb $=0,318 \mathrm{~cd} / \mathrm{m}^{2}$

Fig. 1 .

involves the inferotemporal region of the optic nerve) and there is no other apparent cause such as a disc anomaly or myopic alteration, then the disc can be considered to be definitely glaucomatous. The finding that most certainly points to a definitely pathologic disc, however, is progressive narrowing of the rim (or enlargement of the cup). When gross, such changes can be recognised by comparing drawings of the disc made at different times. Marked alterations can only be appreciated by comparing photographic documentation of the disc appearance. Since such change is the single most valuable criteria in establishing 


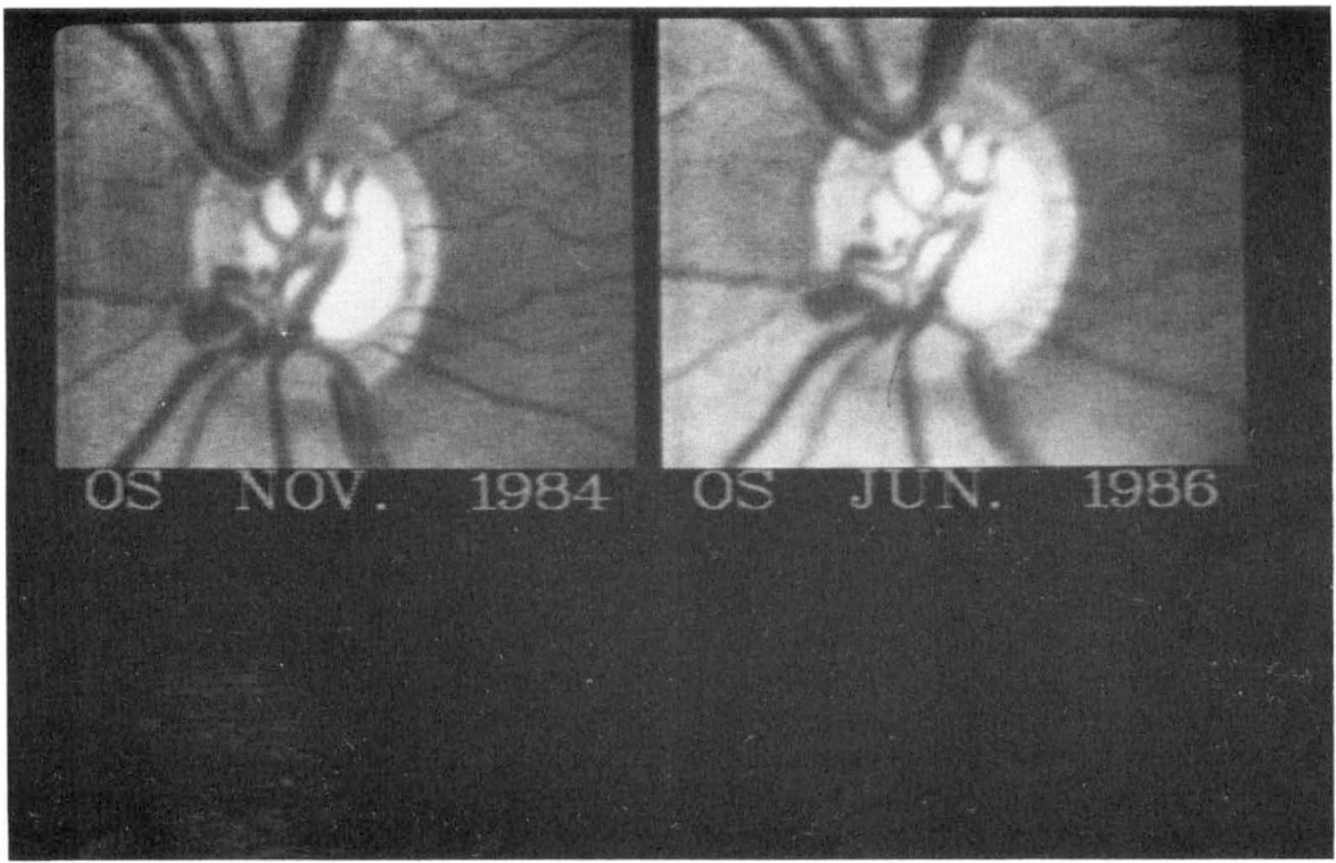

Fig. 2a.
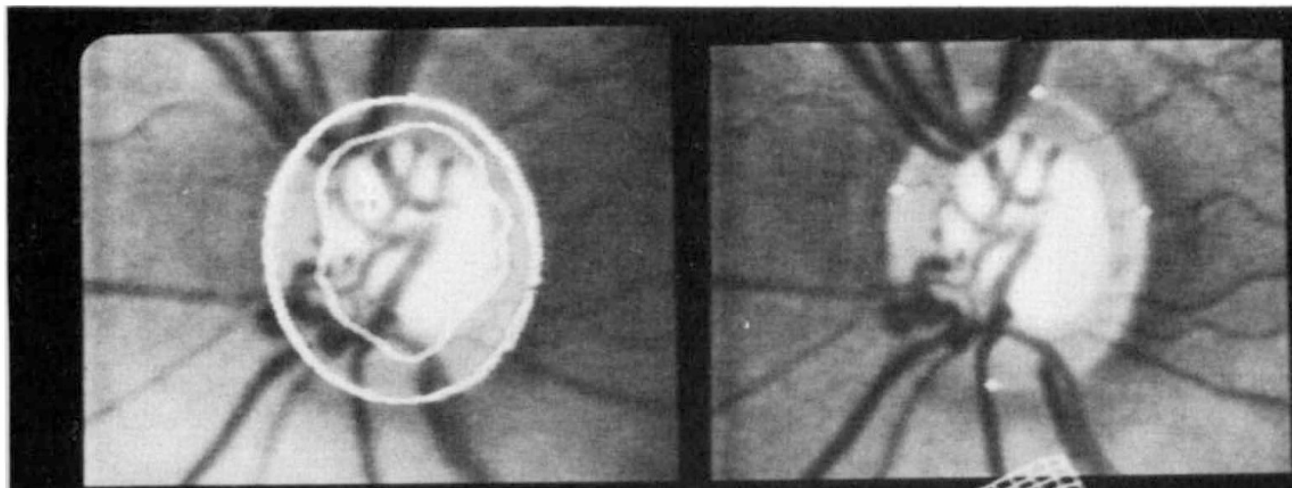

cons $x=$ a. as

$\cos (-5)=0.69$

coesalis = a.5e

ob : 2.es69 .n. so.

CV $=9.2469$ su. win.

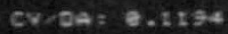

$1-C Y \sim 0 y=$ a.eats

Das = t.ea -in. sa.

eaved = 0.49

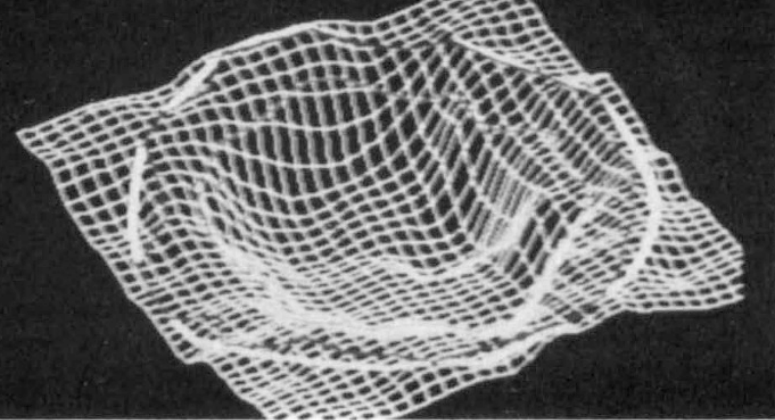

Fig. $2 b$. 


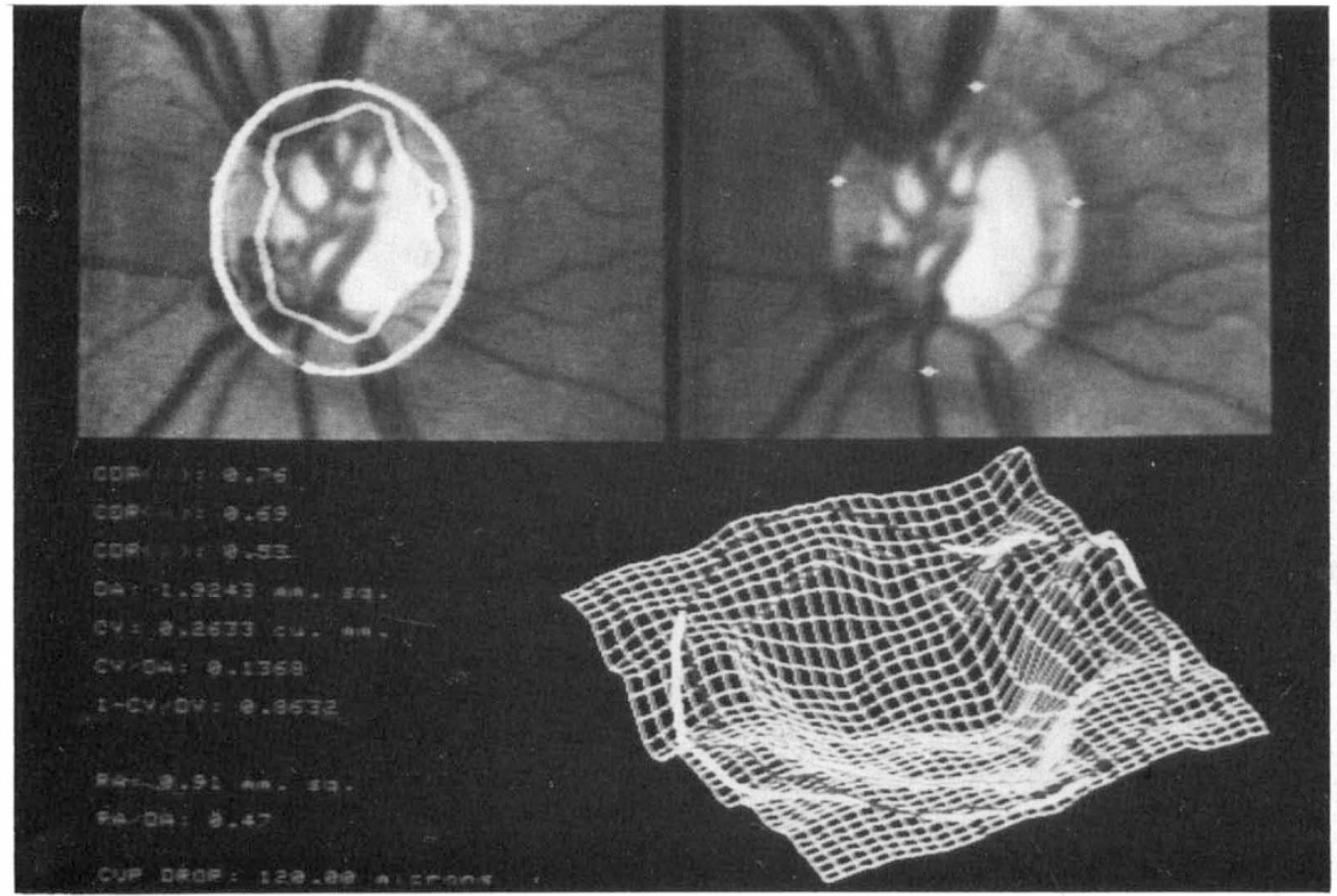

Fig. 2c.

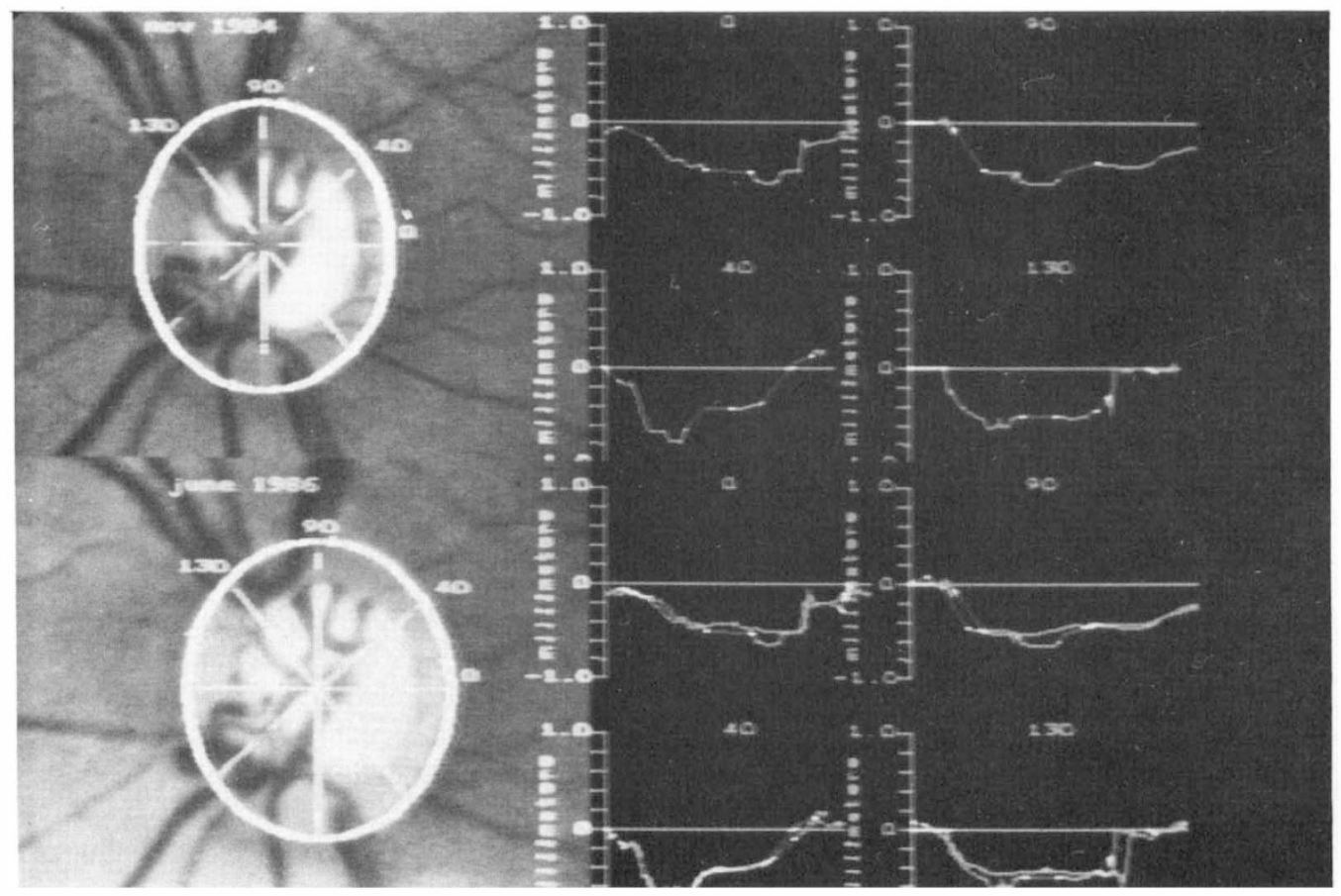

Fig. 2d. 


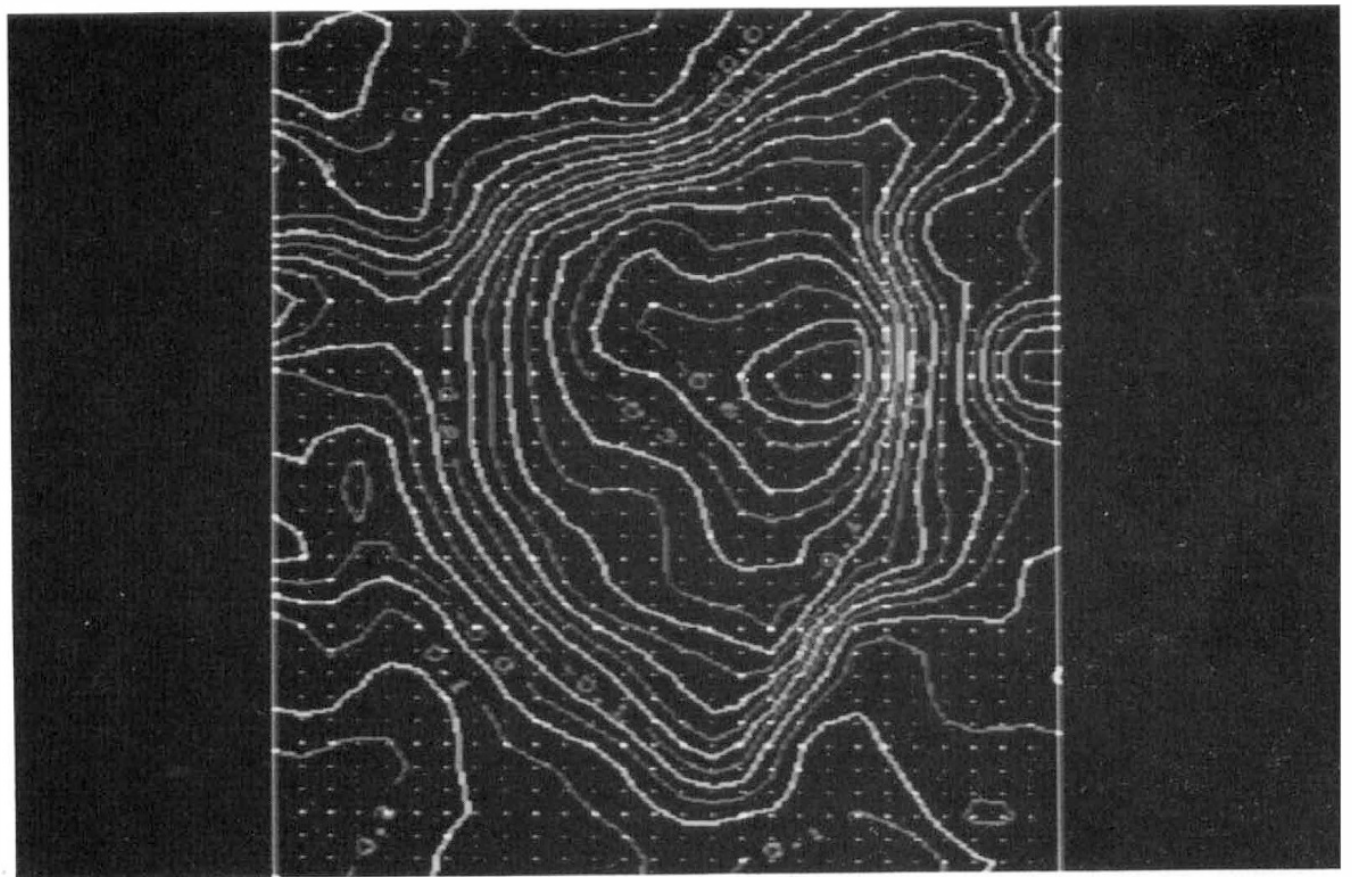

Fig. 2e.

OS JUN.1986

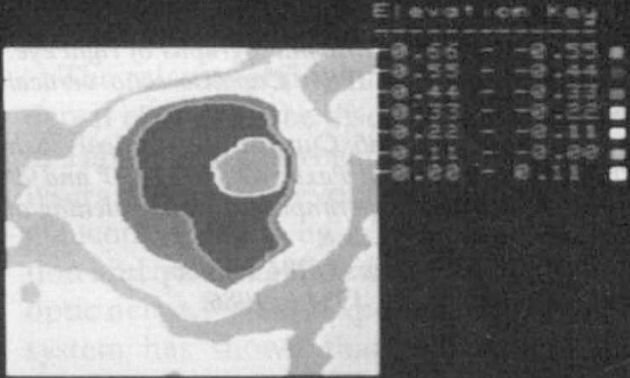

OS NOV.1984

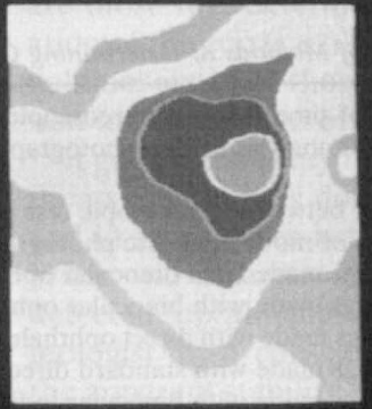

Fig. 2f. 


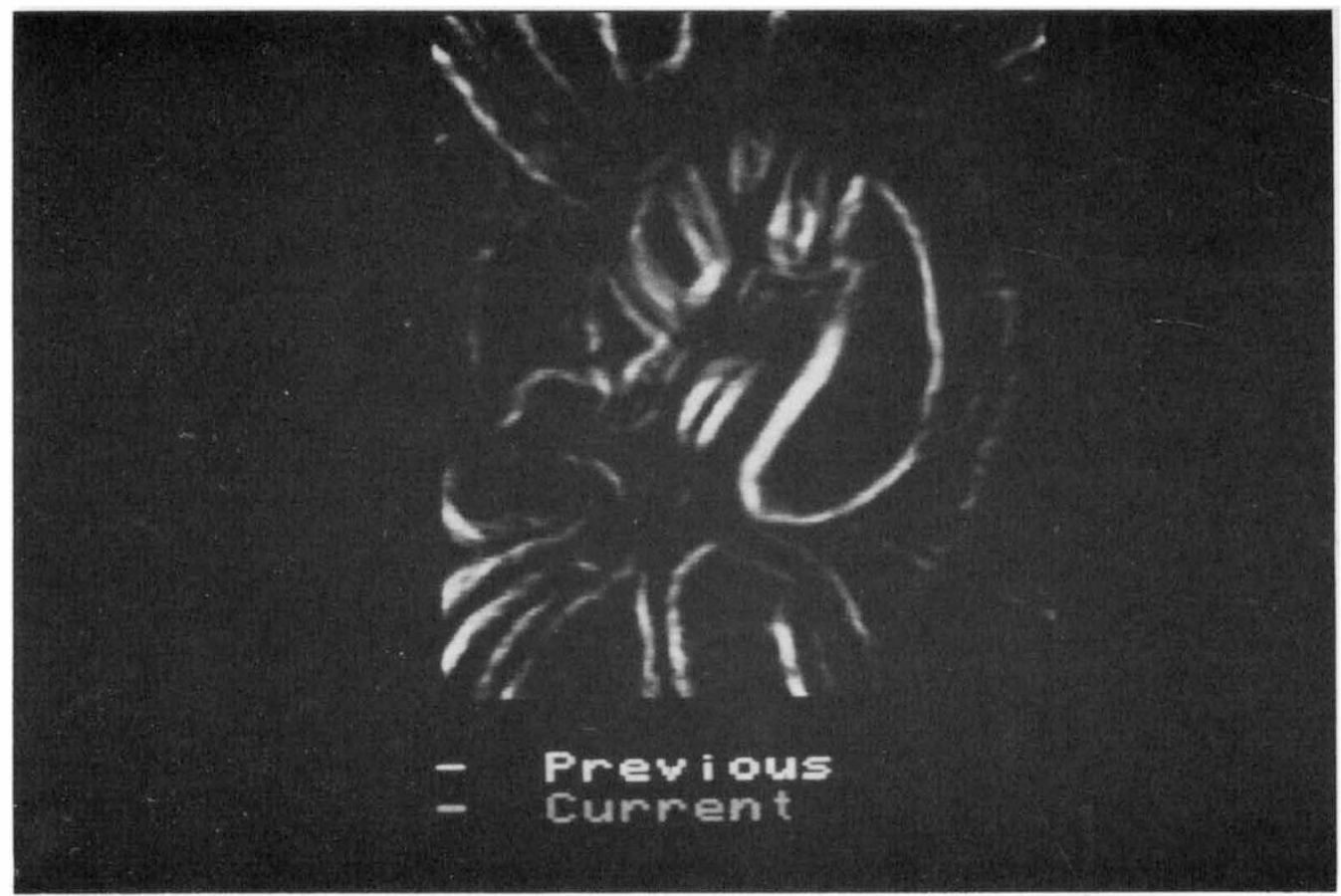

Fig. 2g.

Fig. 2. Each of thousands of individual points in an image can be analysed separately by a computerised image analyser. This transformation into a quantitative format permits statistical analysis of the image. Thus, two different images or aspects of different images can be compared quantitatively. Depicted here is a photograph of an optic disc taken in 1984 and repeated in 1986. Also shown are diagrams of the depth of the disc in cross-section, and contour maps demarcating areas of different depth.

(a) Discs: 1984 and 1986 disc photographs of right eye.

(b) Topography of disc 1984: Cup/disc ratio vertical .75, horizontal .68; rim area 2.1 sq mm; cup volume $.25 \mathrm{cu} \mathrm{mm}$.

(c) Topography of disc 1986: Cup disc ratio vertical .76; horizontal .69; rim area 1.9 sq mm; cup volume .26 cu mm. (d) Profiles of cup shape at 4 axis: $40^{\circ}, 180^{\circ}, 130^{\circ}$ and $90^{\circ}$. Top four on right are of 1984 disc; bottom four are 1984 and 1986 photographs superimposed. Note widening of cup in $130^{\circ}$ axis.

(e) Contour map of 1984 disc.

(f) Comparison of contours, 1984 vs 1986.

(g) Shift of blood vessels, 1984 vs 1986.

Table III Relative Value of Methods of Determining Change in Appearance of the Optic Disc

1. Quantitative analysis of simultaneous stereoscopic images

2. Projection technique of analysis of disc photographs ${ }^{9}$

3. Stereochronoscopy ${ }^{10}$

4. Free-hand comparison between stereoscopic disc photographs

5. Free-hand comparison of monocular disc photographs

6. Comparison of drawings made from binocular ophthalmoscopy with contact lens

7. Comparison of drawings made with binocular ophthalmoscopy with Hruby lens

8. Comparison of drawings made with direct ophthalmoscope with beam narrower than the width of optic disc

9. Comparison of drawings made with standard direct ophthalmoscopy

10. Comparison of drawings made with binocular indirect ophthalmoscopy

11. Comparison of drawings made with monocular indirect ophthalmoscopy 
the presence of glaucoma, the importance of obtaining photographs of the optic nerve head cannot be overstressed.

There are, of course, a variety of nuances in the appearance of the optic disc that make its appearance more or less characteristic of glaucoma. These have been discussed in detail in the past and such clues are important. ${ }^{7-14}$ What is being dealt with here, however, are 'hard' findings that lend themselves to quantification.

Not only are changes in the visual field variable, but they are also subjective and prone to be influenced by a wide variety of factors such as clarity of the media, refractive error, intellectual and emotional state of the patient, competence of the technician, etc. ${ }^{15-19}$ Thus, while a disc photograph can be analysed 'blind' a chart of the visual field without accompanying information is of little help. Where ancillary factors can be eliminated, nerve fibre bundle-type defects larger than five degrees and denser than one-half log unit (5db) may be considered suspicious. When denser than one and half log units $(15 \mathrm{db})$ it is likely that the change is a representation of real pathology, though not necessarily glaucoma.

The standard provocative tests are of little or no help in establishing a valid diagnosis of primary open-angle glaucoma. Their predictive value is so low that they cannot be recommended. Newer tests, such as those that test the compliance of the optic nerve or the response to the visual field to elevated intraocular pressure offer new and exciting possibilities. The reliability of these tests, however, is still unproven.

In assessing the patient with primary openangle glaucoma there are two main questions that need to be answered: Firstly, is change occurring (that is does the patient have an active glaucomatous process), and secondly, what is the rapidity with which the change is occurring? When seeing a patient for the first time and attempting to establish a diagnosis, an effort is made to try to determine if the change occurred prior to the time of that first examination. Thus, the emphasis is on the history and the discovery of clues that suggest that the patient has changed from his or her normal state.

\section{Assessment of the Patient With Established Glaucoma}

Management of glaucoma involves lowering of intraocular pressure to the point that deterioration ceases or, preferably, improvement in the disc or field is noted. Since all methods of lowering intraocular pressure carry with them side-effects, and since (by and large) the more one lowers intraocular pressure the greater the frequency and severity of sideeffects, glaucoma is not appropriately managed simply by attempting to lower intraocular pressure maximally. To do this would inflict many problems that would unnecessarily worsen the quality of life. Therefore, the usual method of treating glaucoma is to lower intraocular pressure to the point that deterioration ceases. Obviously, to make the determination that deterioration has ceased requires the ability to recognise change. Such an ability is directly related to the effort, skill, and facilities employed to search out such change. A small telescope allows visualisation of many stars not able to be seen with the naked eye, a small telescope well used will reveal more stars than the same telescope poorly employed. A larger telescope permits utilisation of still more stars, and so forth.

The relative ability of different methods to detect change in the disc and field is indicated in Table II. In this regard the new image analysers may surely revolutionise the care of the glaucoma patient by making possible detection and quantification of small changes in the optic nerve. ${ }^{20,21}$ Our experience with the PAR system has shown that reproducible, valid measurements can be obtained..$^{22}$

The programs that appear most valuable are those that determine change in configuration of the cup (i.e. not just cup volume, rim volume, etc.) and those that determine alteration in the position of blood vessels.

It goes without saying that the way in which the examination is done is vitally important, and in some cases is the determining factor. When no change in disc appearance is detected ophthalmoscopically the ophthalmologist must consciously consider whether the apparent stability is spurious, due to limitations of the methodology, or is a representation of actual stability of the condition. Only 
the latter can legitimately lead to the conclusion that the patient's condition is actually stable.

The two most sensitive techniques for detecting change both require highly sophisticated instruments which are expensive and not readily available (Figs. $1 \& 2$ ). Simpler, less expensive, and readily available means are, however, also satisfaetory. In the early stages of the disease the disc is likely to change prior to the visual field and assessment of the optic disc is probably the most important part of the evaluation of the patient. Thus, meticulous disc drawings based on properly performed ophthalmoscopy are of value. Only slightly more expensive, but definitely more reliable, are stereoscopic photographs. Once the baseline photograph has been obtained the photographs should be repeated in order to confirm a suspicion of change made on the basis of ophthalmoscopy, to obtain a new baseline after major treatments such as surgery, and at about five year intervals in patients in whom other aspects of the assessment (intraocular pressure, history, and visual field examination) do not suggest a likelihood of deterioration.

In occasional cases the visual field can deteriorate without apparent change in the disc. Thus, field analysis is important even in early stages. While computerised, static, threshhold perimetry using specially designed programs is the most sensitive method of finding such changes, simpler methods such as the Armaly-Drance method of screening using a Goldmann perimeter are quite satisfactory, and when properly performed will not permit the patient to deteriorate significantly from a functional point of view.

In the latest stages of the disease disc changes have become marked and detection of change in the disc becomes increasingly difficult. Consequently, evaluation of the field is the primary method by which stability or deterioration is determined. When the field is down to a few degrees careful evaluation with a Tangent screen at two metres is a highly satisfactory way of plotting the field.

In summary, the factor that most influences the management of the patient with glaucoma is change; the factor that most determines the diagnosis of primary open-angle glaucoma is the presumption of change. Consequently, a primary responsibility of the ophthalmologist diagnosing and managing glaucoma is the estimation of change and the rate at which it occurs. Given this information diagnosis is rational and management is usually successful. Without it, dangerous treatment may be given inappropriately or the condition may be allowed progress unnecessarily.

\section{References}

'Tesluk GC, Spaeth GL: The occurrence of primary open-angle glaucoma in the fellow eye of patients with unilateral angle-cleavage glaucoma. Ophthalmology 1985; 92: 904-11.

${ }^{2}$ Wishart PK, Spaeth GL, Poryzees EM: Anterior chamber angle in the exfoliation syndrome. $\mathrm{Br} \mathrm{J}$ Ophthalmol 1985; 69: 103-7.

${ }^{3}$ Drance SM: Doyne Memorial Lecture: Correlation of optic nerve and visual field defects in simple glaucoma. Trans Ophthalmol Soc UK. 1975, 95: 288-96.

${ }^{4}$ Becker B: Diabetes mellitus and primary open angle glaucoma. The XXVII Edward Jackson memorial lecture. Am J Ophthalmol. 1971, 71: 1-16.

${ }^{5}$ Becker B, Kolker A and Roth D: Glaucoma family study. Am J Ophthalmol. 1960, 50: 557.

${ }^{6}$ Hollows FC and Graham PA: Intraocular pressure, glaucoma, and glaucoma suspects in a defined population. Br J Ophthalmol. 1966, 50: 570.

${ }^{7}$ Read RM and Spaeth GL: The practical clinical appraisal of the optic disc in glaucoma: The natural history of cup progression and some specific disc-field correlations. Trans Am Acad Opthalmol Otolaryng 1974, 78, Op 255-74.

${ }^{8}$ Armaly MF: Cup/disc ratio in early open angle glaucoma. Doc Ophthalmol. 1969: 526-33.

${ }^{9}$ Begg IS, Drance SM and Sweeney VP: Haemorrhage of the disc: A sign of acute ischaemic optic neuropathy in chronic simple glaucoma. Can $J$ Ophthalmol. 1970, 5: 321-30.

${ }^{10}$ Richardson KT: Optic cup symmetry in normal newborn infants. Invest Opthalmol. 1968, 7: 137-40.

${ }^{11 G l o s t e r ~ J: ~ S h a d o w s ~ o n ~ t h e ~ d i s c . ~ P r o c ~} R$ Soc Med. 1971, 64: 938-9.

${ }^{12}$ Hitchings RA, Spaeth GL: The optic disc in glaucoma. 1. Classification. Br J Ophthalmol. 1976, 60: 778-85.

${ }^{13}$ Spaeth GL, Hitchings RA, Sivalingam E: The optic disc in glaucoma: Pathogenetic correlation of five patterns of cupping in chronic open-angle glaucoma. Trans Am Acad Ophthalmol Otolaryngol. 1976, 81: 217-23.

${ }^{14}$ Spaeth GL: Appearance of the optic disc in glaucoma: A pathogenic classification. In New Orleans Academy of Ophthalmology: A Symposium on Glaucoma. CV Mosby, St Louis 1981; pp 114-153.

${ }^{15}$ Werner EB and Drance SM: Early visual field dis- 
turbances in glaucoma. Arch Ophthalmol. 1977, 95: $1173-5$.

${ }^{16}$ Fisher RF: The influences of orbital contours and lid ptosis on the size of the peripheral visual field. Vision Res. 1967, 7: 671-8.

${ }^{17}$ Fisher RF: The variations of the peripheral visual fields with age. Doc Ophthalmol. 1968, 24: 41-67.

${ }^{18}$ Forbes $\mathrm{M}$ : Influence of miotics on visual fields in glaucoma. Invest Ophthalmol. 1966, 5: 139-45.

${ }^{19}$ Bigger JF and Becker B: Cataracts and open-angle glaucoma: The effect of cataract extraction on visual fields. Am J Ophthalmol. 1971, 71: 335-40.
${ }^{20}$ Schwartz B. Symposium: The optic disc in glaucoma New techniques for the examination of the optic disc and their clinical application. Trans Am Acad Ophthalmol Otolaryngol. 1976, 81: 227-37.

${ }^{21}$ Portney GL: Photogrammetric analysis of volume asymmetry of the optic nerve head cup in normal, hypertensive, and glaucomatous eyes. $A m \mathrm{~J}$ Ophthalmol. 1975, 80: 51-55.

${ }^{22}$ Varma, R. Spaeth GL and Cambier J: Reproducibility of measurement of optic disc topography in humans with the PAR image analyzer. In: Varma R and Spaeth.GL: Use of the image analyzer in study of the optic disc. Thorofare, Charles Slack, 1986 (in press). 